\title{
Thermal Properties of Cement Based Composites with Municipal Solid Waste Incinerator Fly Ash Accessed by Two Different Transient Methods
}

\author{
Jan FOřT *, Anton TRNÍK, Lenka SCHEINHERROVÁ, Zbyšek PAVLÍK, \\ Milena PAVLÍKOVÁ, Robert ČERNÝ
}

\author{
Czech Technical University in Prague, Faculty of Civil Engineering, Department of Materials Engineering and Chemistry, \\ Thákurova 7, 16629 Prague 6, Czech Republic
}

cross'ref http://dx.doi.org/10.5755/j01.ms.22.1.7203

Received 28 May 2014; accepted 17 July 2015

\begin{abstract}
Thermal properties of cement composite with Mixed Fly Ash (MFA) from different parts of Municipal Solid Waste Incineration (MSWI) process as a partial replacement of Portland cement are researched in the paper. MFA is applied in the amount of $10 \%, 20 \%$ and $30 \%$ of the mass of cement, while sand and water quantities are kept constant. For the sake of comparison, a reference mixture with Portland cement as the only binder is studied as well. For the characterization of studied materials, their basic physical properties as bulk density, matrix density and total open porosity are measured using gravimetric method combined with helium pycnometry. Among the thermal properties, thermal conductivity, thermal diffusivity and specific heat capacity are accessed by two transient methods having different experimental arrangement and time of measurement. The measured data obtained by the particular methods are compared and the applicability of the methods for the measurement of thermal properties of solid building materials is discussed.

Keywords: cement based composites, mixed fly ash, municipal solid waste incineration, thermal properties, transient methods.
\end{abstract}

\section{INTRODUCTION}

The knowledge in thermophysical properties of porous building materials as thermal conductivity, thermal diffusivity and specific heat capacity represents important information for their effective design and optimal usage in practice. The data on thermophysical parameters find use in the calculation of U-value [1], energy consumption of buildings for heating and conditioning [2], thermal losses, energy audits as well as in the simulation of heat transport in buildings and their particular components [3]. On this account, a number of measuring methods for thermal properties determination was designed and applied in materials research.

Thermal properties in normal temperature range can be measured by a variety of devices utilizing different mathematical and physical principles [4]. The knowledge of temperature distribution in a studied sample is fundamental for most existing methods. An existence and shape of heat source belong to the most important parameters in that respect. Therefore, the methods for measurement of thermophysical parameters are often classified as either sourceless or source techniques.

In the case of sourceless methods, a specimen is put in contact with another substance or environment, which plays a role of an infinite heat reservoir. This kind of methods is, however, very rarely used in the investigations dealing with porous building materials. Techniques based on utilizing a heat source either inside a specimen or on its surface, in both transient and steady-state arrangements are preferred [5].

\footnotetext{
* Corresponding author. Tel.: +420 224354 688; fax : +420 224354446. E-mail address: jan.fort.1@fsv.cvut.cz (J. Fort)
}

The main advantage of the transient methods is shorter measurement time in a comparison with standard steadystate methods. However, their accuracy and reproducibility is often arguable [6]. Among the transient methods, the hot wire method [7], hot ball method [8], step-wise transient method [9], pulse transient method [10], hot plane or disk transient method [11], and laser flash method [12] are frequently used at the investigation of thermal properties of solids.

The steady-state methods for determination of thermal conductivity are often considered as reference methods. A possibility to determine temperature fields and heat fluxes in an easy and precise way belongs to the main arguments for their application. On the other hand, the long measuring time induces problems with heat loss, which may cause significant systematic errors [5]. The measured specimens have usually plate, spherical or cylindrical shape. As for the practical experimental setups, the guarded hot plate arrangement [13] is the most frequently used.

Since the building materials are manufactured mainly on natural basis, their production has harmful effect on the living environment quality. Hence, the ways of the natural sources savings are searched. One of important ways, widely applied in civil engineering for long years, is to replace natural sources with secondary raw materials, i.e. wastes from other processes. Concrete industry is the greatest consumer of this kind of products. Secondary raw materials having pozzolanic or hydraulic properties, such as silica fume [14], fly ashes [15], or metallurgical slags [16] are commonly used as partial Portland cement replacement. The influence of coal BA (bottom ash), granulated blast furnace slag, and a combination of both materials which were used as fine aggregate replacement in concrete mix design was studied by Yüksel et al. [17]. 
They concluded that durable concrete can be produced by using granulated blast furnace slag and BA as fine aggregate. Waste ceramic materials become also cheap alternative as supplementary binder in concrete [18]. The quarry dust, produced during the breaking of stone boulders in stone crushers for producing coarse aggregates, has been used successfully in concrete industry [19].

Instead of above given waste products already reused in building industry, there are also waste materials, which are still not frequently used in practise, because their possible application brings number of potential problems from the point of view of their toxicity, chemical stability, durability etc.

The waste management becomes one of the most actual problems of present society, whereas the amount of disposed waste will be strictly limited in the near future. On that account, especially the combustion method of the waste treatment will become more popular and the increase of the amount of the incineration waste products can be expected. Hence, various methods of using the BA and FA (fly ash) coming from waste incineration plants need to be developed. Incineration byproducts, if reused, will offer many advantages, ensure sustainability, reduce pollution and environmental degradation, generate revenue, and preservation of natural resources, etc. [20]. Solid residuals from waste incineration process are subjected in the last decade to an intensive research focused on their possible application as new concrete mineral admixtures, whereas the residues from the municipal solid waste incineration (MSWI) are most often studied [21]. These materials can play role of active as well of non-active mineral admixture as stated for example in [22, 23].

Since the results of the above given research are very promising from the point of view of the use of MSWI materials in materials production, we focused in the presented paper on experimental research of thermal properties of newly developed composites composed of mixed fly ash (MFA) coming from different parts of MSWI process, Portland cement, and silica sand. Thermal properties of studied materials are accessed by two transient methods having different experimental arrangement and time of measurement. Within the performed research, the data on thermophysical properties of investigated composites measured by applied methods are compared and the effectiveness of testing apparatuses is discussed. The presented work should contribute to the wider utilization of MSWI by products in building materials production with lower environmental impact.

\section{STUDIED COMPOSITES}

Incineration is an often adopted technology for the disposal of municipal solid waste (MSW). Within the incineration process, solid residues composed of BA, FA and scrubber residues are produced [24]. Since the cement solidification/stabilization is certainly one of the most popular techniques for FA treatment, application of FA in cement based composites production looks like a logical solution. In recent studies we already proved the pozzolanic behaviour of MSWI FA [25-27], and described the effect of FA incorporation on composites mechanical and basic physical parameters. In this paper, we focused on determination of thermophysical properties of cement mortar with partial Portland cement replacement by MFA coming from different sections of MSWI process.

Ordinary Portland cement (CEM-I 42.5 R) was used in the experimental study. MFA was applied at 10\%, $20 \%$ and $30 \%$ replacement levels by the mass of cement, while sand and water quantities were kept constant. For the sake of comparison, a reference mixture labeled MR with Portland cement as the only binder was studied as well. The composition of the researched mortar mixtures is given in Table 1.

Table 1. Composition of studied mortars

\begin{tabular}{|c|c|c|c|c|}
\hline \multirow{2}{*}{ Material } & CEM I 42.5R & MFA & Silica sand & Water \\
\cline { 2 - 5 } & \multicolumn{4}{|c|}{ Amount, kg } \\
\hline MR & 4.5 & - & 13.5 & 2.4 \\
\hline MFA10 & 4.05 & 0.45 & 13.5 & 2.4 \\
\hline MFA20 & 3.60 & 0.90 & 13.5 & 2.4 \\
\hline MFA30 & 3.15 & 1.35 & 13.5 & 2.4 \\
\hline
\end{tabular}

Chemical composition of MFA was measured using XRF (X-Ray Fluorescence). MFA was composed mainly of $\mathrm{SiO}_{2}$ (15.6 mass \%), $\mathrm{Al}_{2} \mathrm{O}_{3}(9.2 \%), \mathrm{CaO}$ (23.9\%), $\mathrm{Na}_{2} \mathrm{O}(9.35 \%), \mathrm{K}_{2} \mathrm{O}(6.6 \%)$ and $\mathrm{Cl}^{-}(11.2 \%)$. MFA was characterised by its particle size distribution that was measured on laser diffraction principle using apparatus Analysette 22 MicroTec plus (FRITSCH). The laser analyser allows measurement of grain size up to $2 \mathrm{~mm}$. The obtained data is given in Fig. 1 and Fig. 2. Here, also the results for mixed binder are presented.

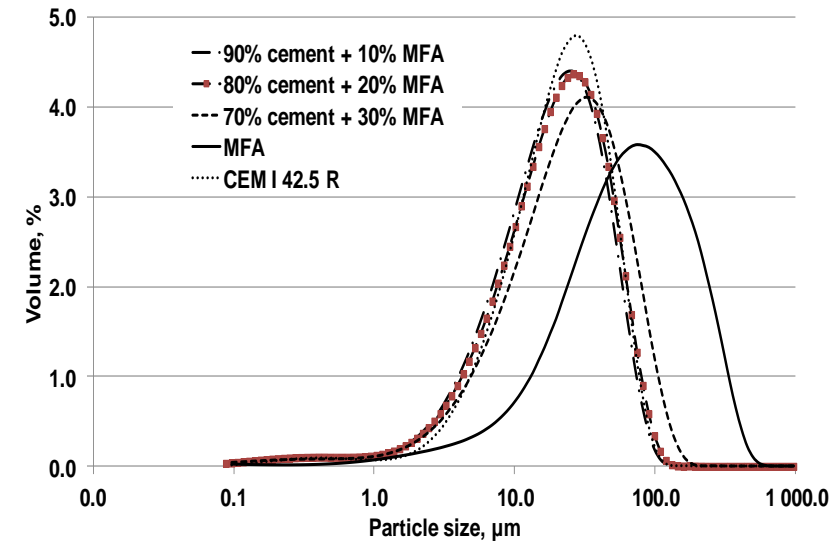

Fig. 1. Particle size distribution - distribution curves

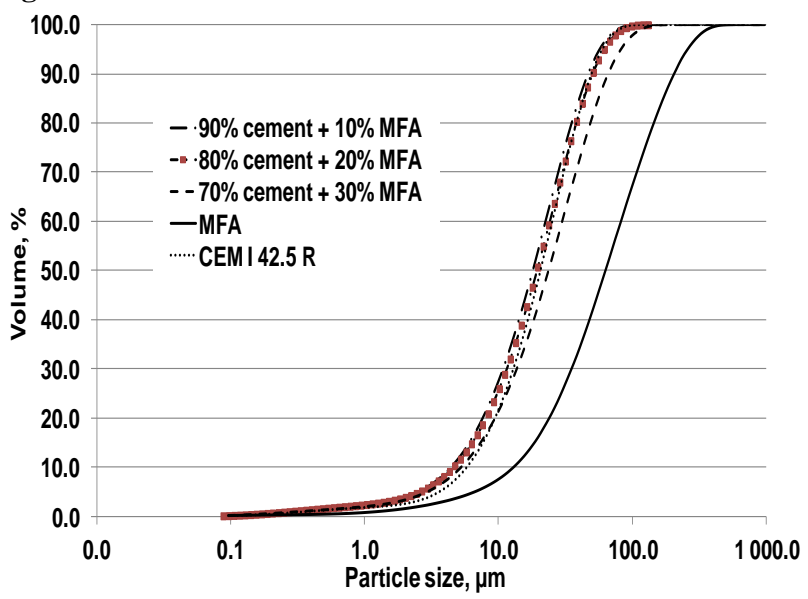

Fig. 2. Particle size distribution - cumulative curves

One can see that the Portland cement was finer, compared to the applied MFA. The maximal amount of 
cement particles ranged between 5 and $100 \mu \mathrm{m}$, whereas the maximal volume of MFA particles was observed in the interval $10-500 \mu \mathrm{m}$. The usage of MFA in the researched binder mixtures led to a certain coarsening of the blended binder. On the other hand, all the blended binders exhibited sufficient fineness for optimal hydration reaction.

\section{EXPERIMENTAL}

Studied mortars were characterised by their bulk density, matrix density, and total open porosity. For the measurement of basic physical properties, there was necessary to cast cubic samples with dimensions of $50 \times 50 \times 50 \mathrm{~mm}$. For each material parameter, five samples were used. Bulk density was determined from the measurement of sample sizes (using digital length meter) and its dry mass. The matrix density was accessed by helium pycnometry using apparatus Pycnomatic ATC (Thermo Scientific). The accuracy of the gas volume measurement using this device is $\pm 0.01 \%$ from the measured value, whereas the accuracy of used analytical balances is $\pm 0.0001 \mathrm{~g}$. On the basis of bulk density and matrix density measurements, the total open porosity was calculated [28]. The relative expanded uncertainty of the applied testing method was expected $5 \%$.

Thermophysical properties of researched materials were accessed by two transient pulse methods using devices Thermophysical Tester RTB (Slovak Academy of Sciences) and Isomet 2114 (Applied Precision, Ltd.). All the performed experiments were done on samples dried at $105^{\circ} \mathrm{C}$.

The principle of RTB apparatus is described in detail in [29]. A heat pulse inside the specimen generates a dynamic temperature field. From the parameters of the temperature response (usually the time $t_{\mathrm{m}}$ and the magnitude $T_{m}$ of the temperature response) to the heat pulse, the specific heat capacity, thermal diffusivity and thermal conductivity can be calculated. Technically, the specimen is cut into three pieces to insert the measuring probes between the cut surfaces. A plane heat source made of thin metallic foil is placed between the first and the second part of the specimen, while a thermocouple is placed between the second and the third part of the specimen (Fig. 3). The heat pulse is generated by the passage of an electrical current through the metallic foil for a short time.

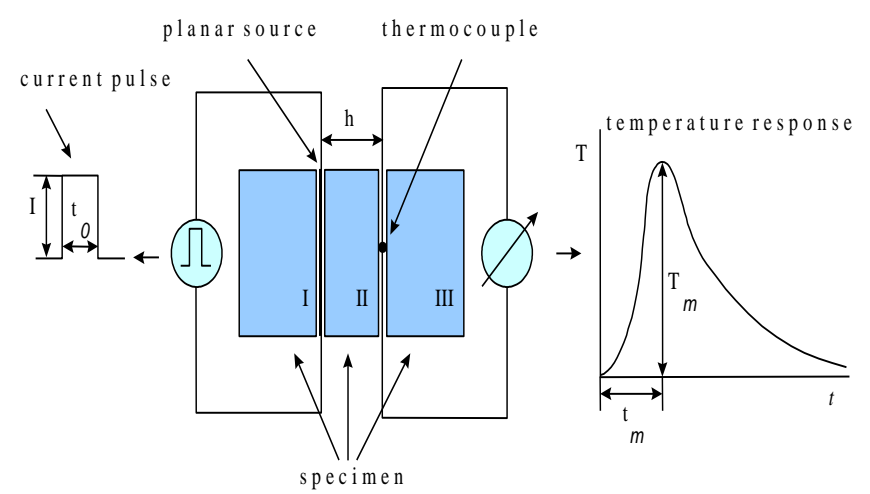

Fig. 3. Scheme of the measuring method

The RTB instrument allows realization of an experiment that is composed of measuring sequences in which all required operations are performed to obtain thermophysical data at specific conditions. Specimen temperature is controlled through heat exchangers temperature control blocks by thermostat. Atmosphere in the specimen surroundings is controlled by vacuum pump. The chamber for sample placing is constructed for temperature range from $-40^{\circ} \mathrm{C}$ up to $120^{\circ} \mathrm{C}$. Two heat exchangers are situated inside the chamber. The temperature of the heat exchangers is controlled by a liquid medium. Thus high temperature stability of the heat exchangers in connection with a thermostat can be achieved. A specimen setup is placed between the heat exchangers. An isothermal cover is used to suppress any temperature gradient along the specimen set. Vacuum cover gives a possibility to perform measurements in vacuum up to $0.1 \mathrm{~Pa}$ or in any atmosphere (air, vacuum, inert atmosphere). The measuring process is controlled by the electronic unit RTLab.

Thermal diffusivity $a\left(\mathrm{~m}^{2} / \mathrm{s}\right)$ is calculated as

$a=\frac{h^{2}}{2 t_{m}}$,

where $h(\mathrm{~m})$ is the specimen thickness, $t_{m}$ (s) the time of maximal temperature response.

Specific heat capacity c $(\mathrm{J} / \mathrm{kgK})$ is defined in Eq. 2.

$c=\frac{Q}{h \rho T_{m} \sqrt{2 \pi e}}$,

where $\rho\left(\mathrm{kg} / \mathrm{m}^{3}\right)$ is material's bulk density and $T_{m}(\mathrm{~K})$ magnitude of the temperature response. Thermal conductivity $\lambda(\mathrm{W} / \mathrm{mK})$ is then calculated from the formula $\lambda=c a \rho$.

The size of the sample placed in the centre was $150 \times 150 \times 30 \mathrm{~mm}$, and the size of the other two samples was $150 \times 150 \times 50 \mathrm{~mm}$. The measurement was performed at room temperature. Within the measurement, three measurement sequences were realised for each studied material, whereas the pulse time was $80 \mathrm{~s}$ and measurement of temperature response was done for 1 hour.

In Table 2 and Fig. 5, there are presented criteria of ideal model and parameters of specimen setup given by RTB producers.

Table 2. Parameters of experimental setup of RTB device

\begin{tabular}{|l|c|}
\hline Setup & Criterion \\
\hline Specimen size & $h<0.4 R$ \\
\cline { 2 - 2 } & $h H / \lambda<0.1$ \\
\cline { 2 - 2 } & $\frac{h, \text { III }>1.4 \mathrm{~h}}{}$ \\
\hline Heat source & $\frac{h c \rho}{2 b c_{0} \rho_{0}}>500$ \\
\hline Heat pulse width & $h \alpha / \lambda<0.1$ \\
\cline { 2 - 2 } & $t_{0}<0.1 t_{m}$ \\
\hline
\end{tabular}

Isomet 2114 is a hand-held measuring instrument for direct measurement of heat transfer properties of a wide range of isotropic materials including cellular insulating materials, plastics, glasses and minerals. It is equipped with two types of measurement probes: needle probes for soft materials, surface probes for hard materials. The device applies a dynamic measurement method, which enables to reduce the period of thermal conductivity 
measurements to approximately $10-15$ minutes [30].

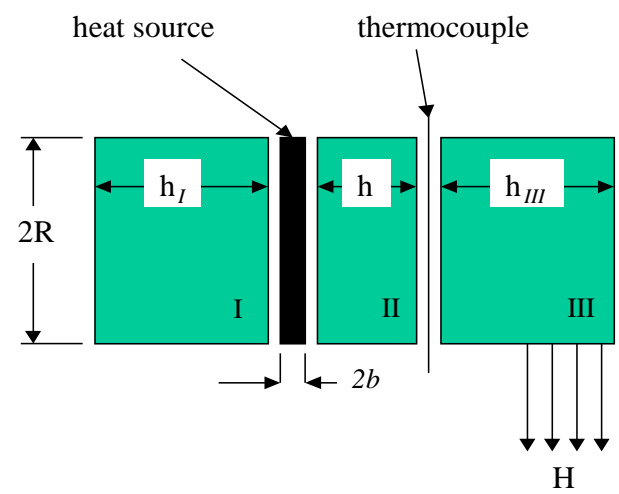

Fig. 4. Criterion of experimental setup

The measurement is based on an analysis of the temperature response of the analysed material to heat flow impulses. Heat flow is excited by electrical heating of resistor heater inserted into the probe which is in direct thermal contact with the tested specimen. Evaluation of thermal conductivity and volumetric heat capacity is based on periodically sampled temperature records as function of time, provided that heat propagation occurs in unlimited medium. The reproducibility of Isomet 2114 for thermal conductivity measurement is $3 \%$ of reading $+0.001 \mathrm{~W} / \mathrm{mK}$ and for volumetric heat capacity $3 \%$ of reading $+1 \times 10^{3} \mathrm{~J} / \mathrm{m}^{3} \mathrm{~K}$. The measurement accuracy given by the producer is presented in Table 3 . The operation temperature of Isomet 2114 is in the range from 0 to $40{ }^{\circ} \mathrm{C}$.

Table 3. Measurement accuracy of Isomet 2114

\begin{tabular}{|c|c|c|}
\hline Measurement & $\begin{array}{c}\text { Measurement } \\
\text { range }\end{array}$ & Accuracy \\
\hline Thermal & $0.015-0.7$ & $5 \%$ of reading +0.001 \\
conductivity & $\mathrm{W} / \mathrm{mK}$ & $\mathrm{W} / \mathrm{mK}$ \\
& $0.7-6.0 \mathrm{~W} / \mathrm{mK}$ & $10 \%$ of reading \\
\hline $\begin{array}{c}\text { Volumetric heat } \\
\text { capacity }\end{array}$ & $4.0 \times 10^{4}-$ & $15 \%$ of reading +1.103 \\
& $4.0 \times 10^{6} \mathrm{~J} / \mathrm{m}^{3} \mathrm{~K}$ & $\mathrm{~J} / \mathrm{m}^{3} \mathrm{~K}$ \\
\hline Temperature & $-20-+70^{\circ} \mathrm{C}$ & $1{ }^{\circ} \mathrm{C}$ \\
\hline
\end{tabular}

In the experiments, board shaped samples having dimensions of $150 \times 150 \times 50 \mathrm{~mm}$ were measured at laboratory conditions at temperature $23 \pm 1{ }^{\circ} \mathrm{C}$ and relative humidity of $30 \pm 5 \%$. Here, surface probes were applied.

\section{RESULTS AND DISCUSSION}

Basic physical properties of researched mortars are summarized in Table 4.

Table 4. Basic physical properties of studied mortars

\begin{tabular}{|c|c|c|c|}
\hline Material & Open porosity, $\%$ & $\begin{array}{c}\text { Bulk density, } \\
\mathrm{kg} / \mathrm{m}^{3}\end{array}$ & $\begin{array}{c}\text { Matrix density, } \\
\mathrm{kg} / \mathrm{m}^{3}\end{array}$ \\
\hline MR & 24.1 & 2011 & 2651 \\
\hline MFA10 & 24.7 & 1949 & 2588 \\
\hline MFA20 & 25.3 & 1917 & 2568 \\
\hline MFA30 & 28.2 & 1832 & 2553 \\
\hline
\end{tabular}

The application of MFA led to the partial decrease in the bulk density and matrix density, whereas this feature was observed for all studied materials with MFA. The total open porosity of materials MR and MFA10 was almost the same, whereas the difference was in the range of measuring error. Materials MFA20 and MFA30 exhibited increase in porosity compared to the reference mixture. The increase in porosity was $\sim 5 \%$ in case of material MFA20, and $\sim 17 \%$ for material MFA30. This finding is of particular importance for further analysis, since the total open porosity significantly affects all material properties related to the durability, mechanical resistivity, heat and moisture transport.

Thermophysical properties data accessed by both measuring methods is given in Table 5, Table 6, Table 7. Here, the presented data represents mean value from 3 measurements. In case of the heat capacity, the original data obtained using Isomet device was divided by the measured values of bulk density in order to calculate the specific heat capacity values.

Table 5. Thermal conductivity of studied mortars

\begin{tabular}{|c|c|c|}
\hline Material & $\begin{array}{c}\text { Isomet thermal } \\
\text { conductivity, W/mK }\end{array}$ & $\begin{array}{c}\text { RTB thermal } \\
\text { conductivity, W/mK }\end{array}$ \\
\hline MR & 1.591 & 1.513 \\
\hline MFA10 & 1.426 & 1.496 \\
\hline MFA20 & 1.311 & 1.344 \\
\hline MFA30 & 0.963 & 0.942 \\
\hline
\end{tabular}

Table 6. Thermal diffusivity of studied mortars

\begin{tabular}{|c|c|c|}
\hline Material & $\begin{array}{c}\text { Isomet thermal } \\
\text { diffusivity, } \cdot 10^{-6} \mathrm{~m}^{2} / \mathrm{s}\end{array}$ & $\begin{array}{c}\text { RTB thermal } \\
\text { diffusivity, } \cdot 10^{-6} \mathrm{~m}^{2} / \mathrm{s}\end{array}$ \\
\hline MR & 0.899 & 0.825 \\
\hline MFA10 & 0.845 & 0.849 \\
\hline MFA20 & 0.768 & 0.758 \\
\hline MFA30 & 0.621 & 0.600 \\
\hline
\end{tabular}

Table 7. Specific heat capacity of studied mortars

\begin{tabular}{|c|c|c|}
\hline Material & $\begin{array}{c}\text { Isomet specific heat } \\
\text { capacity, J/kgK }\end{array}$ & $\begin{array}{c}\text { RTB specific heat } \\
\text { capacity, J/kgK }\end{array}$ \\
\hline MR & 879.5 & 826.2 \\
\hline MFA10 & 865.7 & 916.7 \\
\hline MFA20 & 902.2 & 931.6 \\
\hline MFA30 & 844.3 & 846.8 \\
\hline
\end{tabular}

Looking at the measured thermophysical properties, one can see slight differences between data accessed by RTB device and Isomet 2114. However, the differences are relatively low, typically lower than the measurement accuracy of used devices presented in Table 2. On this account we can conclude that both applied devices can find use in the field of building materials. Looking at to date published papers dealing with application of MSWI waste products in design and production of cement based composites, only durability, mechanical, and microstructure properties are available (see e.g. [31, 32]) and comparison with the other papers are not available. From the quantitative point of view, the heat transport parameters decrease with the increasing amount of used MFA in mortars composition, and corresponds with the data of total open porosity presented in Table 4. Typically, as high decrease in the porosity, as high decrease in the thermal conductivity and diffusivity was identified. This feature is quite common for most porous building materials with high volume of open pores.

\section{CONCLUSIONS}

Experimental assessment of thermal properties of cement based mortars with incorporated MSWI MFA was 
performed by two different transient methods. The obtained data gives information on heat transport and storage properties of researched materials what can be used in building practice as well as in further research aimed at the application of MFA as partial Portland cement replacement. Although this data are crucial for examination of materials application in building practice, also the thermal properties accessed in this paper represent valuable information on materials performance, and can find use for example in the development of composite materials with enhanced thermal insulation properties.

The realised experiments proved the applicability of both devices for the determination of thermal parameters of porous building materials; they were found to provide sufficient resolution and accuracy. The difference between data obtained by both devices were typically lower than $10 \%$, what can be considered as acceptable, in particular taking into account the inhomogeneity of tested materials.

\section{Acknowledgement}

This research has been supported partially by the Ministry of Education, Youth and Sport of the Czech Republic, under project No SGS14/174/OHK1/3T/11, and partially by the Czech Science Foundation, under project No 14-22909S.

\section{REFERENCES}

1. Johansson, P., Geving, S., Hagentoft, C.E., Jelle, B.P., Rognvik, E., Kalagasidis, A. S., Time, B. Interior Insulation Retrofit of a Historical Brick Wall Using Vacuum Insulation Panels: Hydrothermal Numerical Simulations and Laboratory Investigations Building and Environment 79 2014: pp. $31-45$.

2. Ricciardi, P., Belloni, E., Cotana, F. Innovative Panels with Recycled Materials: Thermal and Acoustic Performance and Life Cycle Assessment Applied Energy 134 2014: pp. $150-162$.

3. Van Belleghem, M., Steeman, M., Janssen, H., Janssens, A., De Paepe, M. Validation of a Coupled Heat, Vapour and Liquid Moisture Transport Model for Porous Materials Implemented in CFD Building and Environment 81 2014: pp. 340-353. http://dx.doi.org/10.1016/j.buildenv.2014.06.024

4. Pavlík, Z., Jerman, M., Trník, A., Kočí, V., Černý, R. Effective Thermal Conductivity of Hollow Bricks with Cavities Filled by Air and Expanded Polystyrene Journal of Building Physics 37 (4) 2014: pp. 436-448.

5. Černý, R., Rovnaníková, P. Transport Processes in Concrete Spon Press London 2002.

6. Salmon, D.R., Tye, R.P. An Inter-comparison of a SteadyState and Transient Methods for Measuring Thermal Conductivity of Thin Specimens of Masonry Materials Journal of Building Physics 34 2011: pp. 247-261.

7. Vozár, L. A Computer-Controlled Apparatus for Thermal Conductivity Measurement by the Transient Hot Wire Method Journal of Thermal Analysis and Calorimetry 46 1996: pp. $495-505$.

8. Kubicar, L., Vretenar, V., Stofanik, V., Bohac, V. HotBall Method for Measuring Thermal Conductivity International Journal of Thermophysics 34 2010: pp. $1904-1918$.
9. Zhuo, L., Sukang, Z., Ning, P. Determination of Sample Size for Step-wise Transient Thermal Tests Polymer Testing 31 2009: pp. 307-314.

10. Mňahončáková, E., Jiřričková, M., Pavlík, Z., Fiala, L., Rovnaníková, P., Bayer, P., Černý, R. Effect of Moisture on the Thermal Conductivity of a Cementitious Composite International Journal of Thermophysics 27 2006: pp. $1228-1240$.

11. Suleiman, B. M. Measurements of Thermal Conduction in Partially Saturated Specimens Using the Transient Hot-Disk Technique Journal of Testing and Evaluation 39 (4) 2011: pp. 529-534.

12. Kováč, J., Trník, A., Medved', I., Vozár, L. Influence of Calcite in a Ceramic Body on its Thermophysical Properties Journal of Thermal Analysis and Calorimetry 114 (3) 2013: pp. $963-970$. http://dx.doi.org/10.1007/s10973-013-3084-5

13. Wu, J., Morell, R. Corrections for Thermal Expansion in Thermal Conductivity Measurement of Insulations using the High-Temperature Gurded Hot-Plate Method International Journal of Thermophysics 33 2012: pp. 330-341. http://dx.doi.org/10.1007/s10765-011-1144-2

14. Yazici, H, Deniz, E, Baradan, B. The Effect of Autoclave Pressure, Temperature and Duration Time on Mechanical Properties of Reactive Powder Concrete Construction and Building Materials 42 2013: pp. 53-63.

15. Kwan, A.K.H., Li, Y. Effects of Fly Ash Microsphere on Rheology, Adhesiveness and Strength of Mortar Construction and Building Materials 42 2013: pp. $137-145$ http://dx.doi.org/10.1016/j.conbuildmat.2013.01.015

16. Kim, H.K., Lee, H.K. Effects of High Volumes of Fly Ash, Blast Furnace Slag, and Bottom Ash on Flow Characteristics, Density, and Compressive Strength of HighStrength Mortar Journal of Materials in Civil Engineering 25 2013: pp. $662-665$. http://dx.doi.org/10.1061/(ASCE)MT.1943-5533.0000624

17. Yüksel, I., Turhan, B., Özkan, Ö. Durability of Concrete Incorporating Non-Ground Blast Furnace Slag and Bottom Ash as Fine Aggregate Building and Environment 42 2007: pp. $2651-2659$.

18. O'Farrel, M., Sabir, B.B., Wild, S. Strength and Chemical Resistance of Mortars Containing Brick Manufacturing Clays Subjected to Different Treatments Cement and Concrete Composites 42 2006: pp. 790-799.

19. Nataraja, M.C., Nagaraj, T.S., Reddy, A. Proportioning Concrete Mixes with Quarry Wastes Cement Concrete and Aggregates 23 2001: pp. 81-87.

20. Razak, H.A., Naganathan, S., Hamid, S.N.A. Performance Appraisal of Industrial Waste Incineration Bottom ash as Controlled Low-strength Material Journal of Hazardous Materials 172 2009: pp. 862-867.

21. Sorlini, S., Abba, A., Collivignarelli, C. Recovery of MSWI and Soil Washing Residues as Concrete Aggregates Waste Management 31 2011: pp. 289-297.

22. Bertolini, L., Carsana, M., Cassago, D., Quadrio Curzio, A., Collepardi, M. MSWI Ashes as Mineral Additions in concrete Cement and Concrete Research 34 2004: pp. 1899-1906. http://dx.doi.org/10.1016/j.cemconres.2004.02.001

23. Cheesman, C.R., Makinde, A., Bethanis, S. Properties of Lightweight Aggregate Produced by Rapid Sintering of Incinerator Bottom Ash Resources Conservation and Recycling 43 2005: pp. 147-162. 
24. Cinquepalmi, M.A., Mangialardi, T., Panei, L., Paolini, A.E., Piga, L. Reuse of Cement-solidified Municipal Incinerator Fly Ash in Cement Mortars: PhysicoMechanical and Leaching Characteristics Journal of Hazardous Materials 151 2008: pp. 585-593. http://dx.doi.org/10.1016/j.jhazmat.2007.06.026

25. Pavlík, Z., Keppert, M., Pavlíková, M., Žumár, J., Černý, R. Mechanical, Hygric, and Durability Properties of Cement Mortar with MSWI Bottom Ash as Partial Silica Sand Replacement Cement Wapno Beton 2 2014: pp. $67-80$.

26. Keppert, M., Pavlík, Z., Tydlitát, V., Volfová, P., Švarcová, S., Šyc, M., Černý, R. Properties of Municipal Solid Waste Incineration Ashes with Respect to Their Separation Temperature Waste Management and Research 30 2012: pp. $1041-1048$.

27. Pavlík, Z., Keppert, M., Pavlíková, M., Trník, A., Černý, R. High Temperature Testing of Cement Mortar Containing MSWI Bottom Ash Applied Mechanics and Materials 377 2013: pp. 55-59.

28. Pavlík, Z., Trník, A, Keppert, M., Pavlíková, M., Žumár, J., Černý, R. Experimental Investigation of the Properties of Lime-Based Plaster Containing PCM for Enhancing the Heat Storage Capacity of Building
Envelopes International Journal of Thermophysics 35 (3) 2014: pp. $767-782$.

29. Kubičár, L', Boháč, V., Vretenár, V., Barta, Š. Neure, G., Brandt, R. Thermophysical Properties of Heterogeneous Structures Measured by Pulse Transient Method International Journal of Thermophysics 26 (6) 2005: pp. 1949-1962.

30. Pavlík, Z., Trník, A., Ondruška, J., Keppert, M., Pavlíková, M., Volfová, P., Kaulich, V., Č́erný, R. Apparent Thermal Properties of Phase-Change Materials: An Analysis Using Differential Scanning Calorimetry and Impulse Method International Journal of Thermophysics 34 2013: pp. 851-864.

31. Guo, X.L., Shi, H.S., Hu, W.P., Wu, K. Durability and Microstructure of CSA Cement-based Materials from MSWI Fly Ash Cement and Concrete Composites 46 2014: pp. $26-31$. http://dx.doi.org/10.1016/j.cemconcomp.2013.10.015

32. Shi, P.Y., Lee, P.H., Nian, K.J., Lee, T.C. Characterization of Mortar Made with Cement and Slag Vitrified from a MSWI Ash-mix and CMP Sludge Construction and Building Materials 38 2013: pp. 22-30.

http://dx.doi.org/10.1016/j.conbuildmat.2012.07.083 